
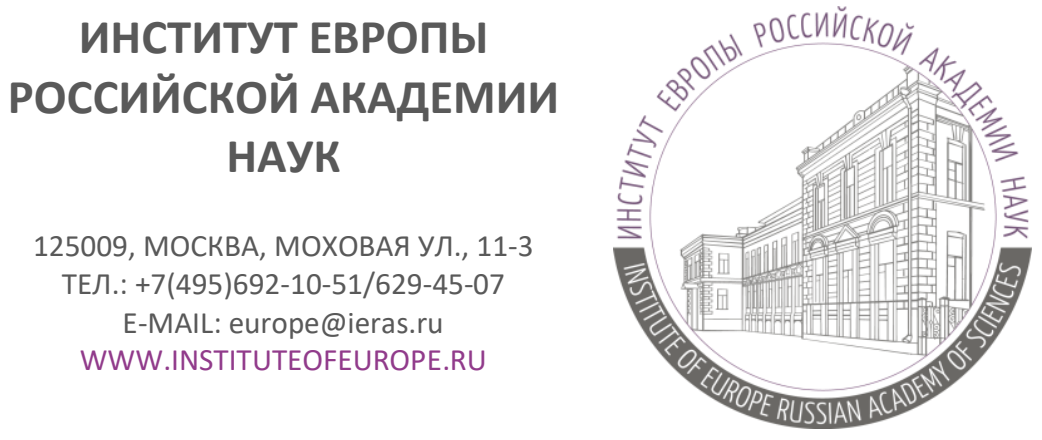

Аналитическая записка №18, 2020 (№201) ${ }^{1}$

\title{
COVID-19 как зеркало цифровой трансформации Германии
}

\section{Владислав Борисович Белов}

кандидат экономических наук, ведущий научный сотрудник, заместитель директора по научной работе, заведующий Отделом страновых исследований, руководитель Центра германских исследований Института Европы РАН

\begin{abstract}
Аннотация. Цифровая трансформация уже несколько лет является «больным ребёнком» правительства Германии. Несмотря на многочисленные инициативы, пакты, программы и мероприятия "Большой коалиции», находящейся у власти с декабря 2013 г., ФРГ по уровню дигитализачии существенно уступает другим ведущим промышленным державам. Кризисные процессы, вызванные пандемией коронавируса, ещё сильнее обнажили существующие дефицить ицифровизации во всех сферах экономики $и$ политики Германии. $B$ записке анализируется их актуальное состояние и перспективы дальнейтего развития, в т.ч. в контексте кооперащии ФРГ и РФ.
\end{abstract}

Ключевые слова: Германия, ФРГ, Евросоюз, кризис, пандемия, коронавирус COVID-19, uифровая трансформачия, дигитализация.

\section{Краткая предыстория цифровой трансформации}

В Германии термины «дигитализация» и «цифровая трансформация», будучи синонимами, появились в 2011 г. Они непосредственно связаны с понятиями

\footnotetext{
${ }^{1}$ DOI: http://doi.org/10.15211/analytics 182020
} 
«Промышленность 4.0» и «Четвёртая промышленная революция», грядущее наступление которой в своей статье 2 апреля, накануне открытия очередной Ганноверской ярмарки, предсказали Х. Кагерманн, В. Вальстер и В.-Д. Лукас² .

Основная идея авторов состояла в необходимости реиндустриализации немецкой экономики за счёт использования кибер-физических систем, связывающих машины и оборудование в единую сеть через интернет. Эти системы позволят с помощью искусственного интеллекта перейти на качественно новый уровень управления производственными процессами/цепочками за счёт самоорганизации, автономизации и оптимизации принятия решений, что качественно изменит поведение человека управленца, работника и потребителя. Используемые при этом другие цифровые понятия - интернет-вещи; умные фабрики и заводы; большие данные; сетевизация; облака и облачные вычисления - впоследствии были перенесены на все народнохозяйственные и общественные сферы.

Разработанная в 2013 г. немецким правительством стратегия «Индустрия 4.0», была взята на вооружение (иногда скопирована) многими странами $\mathrm{EC}^{3}$. Однако, став фундаментом государственной концепции цифровизации и перехода к обществу, основанному на знаниях, она постепенно уступила ведущее место в дигитальном дискурсе другим важным темам, в первую очередь, искусственному интеллекту (ИИ), подготовке специалистов, профильным научным исследованиям и созданию дигитальной технической инфраструктуры, в развитие которых государство за последние годы инвестировало миллиарды евро.

\section{Цифровизация и Большая коалиция}

Несмотря на большие госинвестиции, 2013-2017 годы по сути оказались потерянными с точки зрения достижения амбициозных цифровых целей правительства «Большой коалиции» - в основном из-за неэффективной работы федерального министерства транспорта и дигитализации, а также недостаточной координации многочисленных структурных подразделений других министерств и ведомств, отвечающих за вопросы дигитализации. С учётом негативного опыта новое правительство (в том же партийном составе - ХДС/ХСС и СДПГ) в марте 2018 г. ввело пост министра по цифровизации (Д. Бэр $)^{4}$. Также был создан Комитет по цифровой трансформации, куда вошли А. Меркель и все федеральные министры. Куратором цифровых инициатив стал руководитель Ведомства федерального канцлера Х. Браун. В коалиционном соглашении партнёры

\footnotetext{
${ }^{2}$ См.: Белов В.Б. Новая парадигма промышленного развития Германии - стратегия “Индустрия 4.0” // Современная Европа. № 5. 2016. - С. 11-22

${ }^{3}$ См.: Белов В.Б. Цифровая трансформация европейской промышленности // Европа между трех океанов : монография / [Ал.А. Громыко, В.В. Журкин, В.П. Федоров и др.] ; под общ. ред. Ал.А. Громыко и В.П. Федорова. — М. : ИЕ РАН : Нестор-История, 2019. — С. 363-378

4 Предприниматели и эксперты требовали создать не только пост министра, но и специальное министерство по цифровизации, подписав в интернете соответствующую петицию. См.: Gesucht: Digitalminister (m/w). URL: https://digitalministerium.org/ (дата обращения: 20.04.2020)
} 
зафиксировали пункт о создании портала «цифрового правительства» и призвали унифицировать национальные и европейские правила цифровой экономики 5 .

В ноябре 2018 г. второй Цифровой саммит в Нюрнберге одобрил Национальную стратегию по развитию технологий в области ИИ, уделив особое внимание их безопасному внедрению ${ }^{6}$. В декабре министры экономики Германии и Франции в совместном коммюнике подчеркнули важность кооперации в сфере ИИ. В январе 2019 г. в Ахене Берлин и Париж подписали новый Договор о дружбе и интеграции, в который вошло положение о кооперации в сфере ИИ 72019 год был объявлен в Германии Годом Искусственного интеллекта, в рамках которого прошло более сотни различных мероприятий, создан ряд научных исследовательских центров и разработаны новые образовательные программы. В октябре в Дортмунде прошёл третий Цифровой саммит, на этот раз посвящённый перспективам развития платформенной экономики. В ноябре Федеральное министерство экономики и энергетики приняло новую промышленную стратегию, содержащую важные положения в отношении ИИ ${ }^{8}$. Многие германо-французские предложения по цифровизации вошли в аналогичную стратегию Евросоюза (март 2020 г.), а также в Европейскую зелёную сделку (декабрь 2019 г.).

\section{Дефициты дигитализации и рейтинги цифровой конкурентоспособности ФРГ}

Несмотря на определённые успехи, качественного прорыва в цифровой сфере ФРГ в 2018-2019 гг. не произошло. Германский бизнес по-прежнему требует от государства ускорять повсеместное внедрение широкополосного интернета ${ }^{9}$ помогать при подготовке квалифицированных кадров и обеспечивать защиту личных данных. Показательно, что в рамках предвыборной кампании в Европарламент (май 2019 г.) тема цифровизации в отличие от климата (48\% электоральных предпочтений),

\footnotetext{
${ }^{5}$ См. также: Супян Н.В. Цифровые цели большой коалиции // Научно-аналитический Вестник ИЕ РАН. №2, 2018. - C. 159-167. DOI: http://dx.doi.org/10.15211/vestnikieran2201824 (дата обращения: 20.04.2020)

${ }^{6}$ Первый Цифровой саммит (Digital-Gipfel) состоялся в июне 2017 г. в Людвигсхафене. В нём приняли участие более тысячи бизнесменов, политиков, экспертов и представителей науки, образования и профсоюзов. Ранее такие встречи назывались «Национальный IT-саммит»- к начало 2017 г. в этом формате прошло 10 мероприятий. В рамках нового формата ведется работа 10 взаимосвязанных платформ: цифровые сети и мобильность; инновационная оцифровка экономики; стратегия «Индустрия 4.0»; обучающиеся системы; цифровой мир труда; цифровое управление и государственные информационные технологии; «Учиться. Исследовать. Знать»; культура и средства массовой информации; безопасность, защита и доверие для общества и бизнеса; политика потребителей в цифровом мире.

7 См.: Белов В.Б. Актуальные вызовы и задачи хозяйственно-политического тандема Германии и

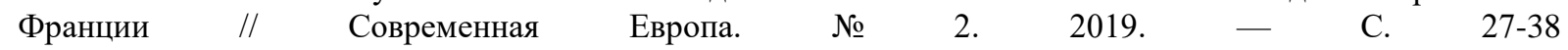
DOI: http://dx.doi.org/10.15211/soveurope220192738

${ }^{8}$ Белов В.Б. Германия - сложный поиск новой промышленной стратегии // Современная Европа. № 4. 2019. - C. 27-36 DOI: http://dx.doi.org/10.15211/soveurope420192736

${ }^{9}$ В 2019 г. ФРГ по доле волоконно-оптических соединений на существующих широкополосных разъёмах $(3,6 \%)$ занимала одно из последних мест среди стран ОЭСР. Для сравнения: у лидера - Сингапура $81,7 \%$, Японии - 79, Швеции - 68,9, Испании - 62,5, Финляндии - 52,7, Португалии - 48,2, Франции 19,8, США - 15,6, Италии - 6. Среднее по ОЭСР - 26,8\%. Источник: www.de.statista.com (дата обращения: 20.04.2020)
} 
социальной безопасности (43\%), сохранения мира (35\%) и миграции $(25 \%)$ германского избирателя не интересовала. Одновременно, согласно опросу Фонда имени Фридриха Эберта, 46\% граждан ФРГ были убеждены в пользе дигитализации. В январе 2020 г. Европейский центр цифровой конкурентоспособности (European Center for Digital Competitiveness) опубликовал доклад ${ }^{10}$ (Digitalreport 2020), согласно которому 89\% респондентов считали, что государство и экономика ФРГ существенно отстали в цифровой трансформации. Полагая, что федеральное правительство должно вносить основной вклад в эти процессы, большинство сочло его усилия недостаточными, отметив отсутствие чёткой концепции и невысокую цифровую компетентность профильных министров.

Германия уступала США и Китаю как по количеству суперкомпьютеров - 14 против 119 и 219 соответственно, так и по объёму инвестиций в квантовые технологии -722 млн долл. против 1,2 млрд и 10 млрд долл. ФРГ существенно отстаёт от лидеров по уровню рискованного финансирования и количеству инновационных стартапов. По данным инфраструктурного банка Kreditanstalt für Wiederaufbau, только 30\% малых и средних предприятий страны доводят свои цифровые проекты до стадии конечной реализации. Уровень цифровизации госуслуг составляет только 46\% по сравнению с $67 \%$ во Франции и 77\% в Нидерландах. По данным союза IT-компаний ВITCOM 22\% фирм в ФРГ участвуют в дискуссиях на тему ИИ, но лишь 6\% используют его технологии.

На фоне отсутствия прогресса в сфере дигитализации международные рейтинги цифровизации ФРГ в последние годы были невысокими. По данным Центра исследования международной конкурентоспособности IMD, в 2019 г. по показателю цифровой конкурентоспособности ФРГ была 17-ой среди 63 стран в мире. Согласно общему индексу DESI, оценивающему состояние дигитализации в государствах-членах EC, Германия в 2019 г. занимала 12-ю из 28 позиций. По некоторым параметрам, например, по использованию облачных технологий, отставание было еще больше.

\section{Пандемия как акселератор дигитализации}

Кризисные процессы, вызванные пандемией коронавируса, ещё сильнее обнажили существующие дефициты цифровизации общественно-политических, хозяйственных и научно-образовательных процессов в Германии, одновременно ускорив так называемую принудительную дигитализацию. Ограничительные меры федерального и земельных правительств в марте 2020 года обусловили вынужденный переход многих граждан на дистанционную работу, побудив их организовать «домашний офис». Резко возросло использование различных платформ, позволяющих проводить онлайн обсуждения, встречи, конференции и обучение. Аналогично выросла популярность досуговых платформенных сервисов, в первую очередь, для просмотра кино, спектаклей, выставок и музеев. Соответственно, увеличилась нагрузка на

\footnotetext{
${ }^{10}$ В докладе анализируются результаты репрезентативного опроса, проведённого среди граждан ФРГ и ведущих политиков и бизнесменов в октябре-ноябре 2019 г. См.: Digitalreport 2020. - Berlin : European Center for Digital Competitiveness by ESCP Business School. Januar 2020. - 15 S.
} 
существующие сети и интернет-провайдеров, ещё раз показавшая существующие «белые пятна» в передаче данных.

Многие предприятия розничной торговли перешли к преимущественной оплате товаров безналичными, в т.ч. через мобильные телефоны. Многие граждане ФРГ, предпочитавшие до этого наличные, оценили преимущества бесконтактных платежей. В 2019 г. только 15\% покупателей в ФРГ пользовались этой технологией.

Существенная нагрузка легла на медицинские учреждения, во многих из которых приём пациентов до сих подтверждается бумажными документами, в т.ч. по факсу ${ }^{11}$. На повестку дня был поставлен вопрос об ускоренном повсеместном внедрении электронного документооборота. Одновременно хорошо зарекомендовала себя находящаяся на высоком уровне немецкая телемедицина.

Конкретным содержанием стало наполняться понятие «цифровых государственных услуг», особенно на уровне земель, которые первыми в начале марта начали оказывать посильную финансовую помощь самозанятым, микропредприятиям и малому бизнесу. В конце марта земли начали распределять средства, предусмотренные федеральными программами поддержки указанных групп. Документы принимались через подачу в электронном виде. В первые дни многие специализированные порталы были вынуждены приостановить свою работу, не выдержав потока обращений.

В апреле государство приступило к тестированию приложения для мобильных телефонов, позволяющего на обезличенной основе определять возможные контакты его обладателя с носителями коронавируса. Речь идёт о разработке научного коллектива Института имени Генриха Герца по телекоммуникациям Общества Фраунгофера в Берлине PEPP-PT (Pan-European Privacy-Preserving Proximity Tracing) ${ }^{13}$. Авторы заверяют, что, по сравнению с аналогами, РЕРР-РТ имеет высокий уровень защиты личных данных, позволяющей сохранить полную конфиденциальность пользователей.

Но именно этот вопрос стал «камнем преткновения» в экспертном дискурсе, создав проблемы для быстрого и масштабного внедрения нового продукта. Немецкое общество весьма щепетильно относится к теме защиты персональной информации как неотъемлемой части свободы индивидуума. Это становится одним из препятствий для внедрения различных цифровых технологий, затрагивающих неприкосновенность личности ${ }^{14}$. В дискуссиях всё чаще появляется понятие «прозрачного как стекло» гражданина/клиента/пациента, каковым он становится, передавая свои данные для использования в цифровом пространстве, в т.ч. в рамках борьбы с коронавирусом. Граждане видят высокие риски в невозможности их стопроцентной защиты и, соответственно, высокой вероятности их противозаконной утечки и использования.

Очевидной стала уязвимость упомянутых выше коммуникационных платформ, например, наиболее доступной - Zoom, уровень шифрования которой оказался очень

\footnotetext{
11 Этой технологией до сих пор активно пользуются около 2/3 предприятий промышленности ФРГ.

${ }_{13}^{13}$ Описание инициативы см.: https://www.pepp-pt.org/

14 Немцы говорят об «информационных следах», которые они оставляют при посещении интернетсайтов, банках данных кредитных и страховых компаний, у врачей, провайдеров телефонных сетей и т.д.
} 
низким. Возросло критическое отношение к использованию бесплатных мессенджеров $^{15}$. Из-за проблем с их безопасностью правительство приняло решение о разработке собственных продуктов. Ведомство по делам канцлера во время пандемии коронавируса рекомендовало своим сотрудникам пользоваться коммуникационным приложением, специально разработанным для них берлинской фирмой Wire ${ }^{16}$.

И для Брюсселя ${ }^{17}$, и для Берлина ${ }^{18}$ это вопрос приоритетный. Помимо совершенствования нормативно-правовой базы государство активизирует поддержку НИОКР по созданию высокоэффективных средств кибербезопасности - одного из краеугольных камней стратегии «Индустрия 4.0» и технологий ИИ. 8 апреля А. Меркель вместе с министрами образования и научных исследований А. Карличек и цифровизации Д. Бэр провела видеоконференцию с представителями ведущих структур, занимающихся ИИ. Особое внимание было уделено необходимости уточнения правительственной стратегии развития ИИ и усиления координации работы существующих центров, в т.ч. между ФРГ и Францией. Была высказана идея использования ИИ и суперкомпьютеров для моделирования возможных эпидемий и пандемий в будущем.

\section{Выводы}

Проявившиеся за несколько недель пандемии коронавируса недостатки дигитализации были известны политикам и экспертам и раньше, но, несмотря на это, их устранение шло очень медленно, что в последние годы привело к падению дигитальной конкурентоспособности экономического лидера ЕС. Коронавирусный шок с большой долей вероятности будет содействовать изменению такого статус-кво.

Уже во второй половине 2020 года следует ожидать активизации НИОКР в основных сферах цифровизации. Начнётся сертификация технологий ИИ, которые могут для использоваться в промышленности и сельском хозяйстве. Усилится сетевое взаимодействие в рамках существующей кооперации немецких и французских научных центров ИИ и, возможно, создана совместная структура по координации их работы. Ещё больше внимания будет уделяться вопросам интернет-безопасности и защиты данных, внедрению электронного документооборота и дигитализации госуслуг.

\footnotetext{
${ }^{15}$ Комиссия ЕС ещё в феврале 2020 г. рекомендовала сотрудникам прекратить пользоваться ненадёжным мессенджером WhatsApp и перейти на некоммерческий Signal, созданный инициативной группой специалистов по защите данных и IT-безопасности. Его программный код доступен в формате Open Source, что позволяет постоянно совершенствовать его защиту. По мнению экспертов, слабые места есть у мессенджеров Viber и ICQnew. См.: Гункель Е., Неринг К. Мессенджеры и защита данных: что больше подходит для работы на дому? 20.04.2020 URL: https://www.dw.com/ru/мессенджеры-и-защита-данныхчто-больше-подходит-для-работы-на-дому/а-53163553 (дата обращения: 20.04.2020)

${ }^{16}$ Там же

${ }^{17}$ В 2021 г. Европейская комиссия планирует принять Закон о цифровых услугах (Digital Services Act), предусматривающий более жёсткое регулирование вопросов защиты данных

${ }_{18} \mathrm{~B}$ Германии существует должность Уполномоченного федерального правительства по защите личных данных. В настоящее время её занимает У. Кельбер.
} 
Вновь возрастёт внимание к стратегии «Индустрия 4.0», с помощью которой компании могут оптимизировать глобальные цепочки стоимости, в т.ч. в рамках решоринга переноса части производственных процессов в Германию. Это касается также малых и средних фирм, многие из которых пока занимают выжидательную позицию в сфере внедрения кибер-физических систем, созданию цифровых двойников и т.д.

Первые итоги «принудительной цифровизации» на фоне пандемии будут подведены 19 июня во время проведения Федеральным министерством внутренних дел, строительства и Родины «Общенационального Цифрового Дня 2020 года» (Digitaltag 2020). Это будет открытое дискуссионное пространство с неограниченным числом онлайн-участников, которые наряду с организаторами уже формируют программу мероприятия, предлагая собственные виртуальные площадки и специальные темы для обсуждения ${ }^{19}$.

Участники Германо-российской инициативы по дигитализации (GRID) также могут подать свои тематические заявки на дискуссии в этом уникальном мероприятии с предложением провести их модерацию. Целесообразно предложить обсуждение перспектив кооперации компаний ФРГ и РФ в сфере защиты индивидуальных и корпоративных данных, цифровизации энергетических и транспортных систем, совместных экологических проектов, исследований ИИ. Во всех этих сферах уже есть конкретные наработки, которые можно существенно углубить и расширить.

По всей видимости, вопросы влияния пандемии на дигитализацию будут в центре внимания четвёртого Цифрового саммита, который в 2020 г. пройдёт в восточногерманском городе Йена. Немецкие представители GRID (например, Siemens и SAP) могли бы по итогам открытого обсуждения в июне пролоббировать включение наиболее актуальных вопросов дигитальной кооперации в одну из десяти дискуссионных платформ.

Ситуацию в сфере цифровой трансформации надо использовать для интенсификации взаимодействия профильных министерств, ведомств и учреждений РФ и ФРГ. Эти вопросы достойны повестки дня очередных заседаний Российско-Германской рабочей группы высокого уровня по экономике и финансам, а также Смешанной комиссии по научно-техническому сотрудничеству, отвечающей за реализацию «дорожной карты» перекрёстного Года научно-образовательных партнёрств.

Цифровая компетентность федеральной, земельной и муниципальной власти, а также граждан всех возрастов за несколько недель пандемии существенно выросла и продолжит укрепляться ${ }^{20}$. Соответственно, будет повышаться профессиональный уровень общественно-политической дискуссии по различным аспектам дигитализации, которая окажет влияние на предстоящую в 2021 г. кампанию по выборам в Бундестаг.

Abstract. Digital transformation has been the «poor child» of German government for several years. Despite numerous initiatives, pacts, programs and rulings of the Grand Coalition, in power since

\footnotetext{
${ }^{19}$ Cм.: https://digitaltag.eu/

${ }^{20}$ Но общая консервативность менталитета немцев будет сохраняться ещё долгие годы
} 
December 2013, Germany's world rankings in terms of digitalization are significantly inferior to other leading industrial states. The crisis caused by coronavirus pandemic has exposed the existing deficits in digitization political and economic processes in Germany. This paper analyzes the current state and prospects for further development, including the context of cooperation of Germany and Russia.

Keywords: Germany, EU, crisis, pandemic, coronavirus COVID-19, digital transformation, digitalization.

Дата выпуска: 21 апреля 2020 года.

Материал доступен для скачивания по адресу: www.instituteofeurope.ru/publications/analytics 